\title{
Trivium
}

Revue franco-allemande de sciences humaines et sociales - Deutsch-französische Zeitschrift für Geistesund Sozialwissenschaften

$12 \mid 2012$

La sociologie de la culture en Allemagne

\section{Un chantier multiforme. État des lieux de la sociologie de la culture dans l'espace germanophone}

\section{Winfried Gebhardt}

Traducteur : Pierre Rusch

\section{OpenEdition}

\section{Journals}

Édition électronique

URL : http://journals.openedition.org/trivium/4378

DOI : $10.4000 /$ trivium.4378

ISSN : 1963-1820

Éditeur

Les éditions de la Maison des sciences de l'Homme

Référence électronique

Winfried Gebhardt, « Un chantier multiforme. État des lieux de la sociologie de la culture dans l'espace germanophone », Trivium [En ligne], 12 | 2012, mis en ligne le 20 décembre 2012, consulté le 07 septembre 2020. URL : http://journals.openedition.org/trivium/4378 ; DOI : https://doi.org/10.4000/ trivium. 4378

Ce document a été généré automatiquement le 7 septembre 2020

\section{(c) (i) (9)}

Les contenus des la revue Trivium sont mis à disposition selon les termes de la Licence Creative Commons Attribution - Pas d'Utilisation Commerciale - Pas de Modification 4.0 International. 


\title{
Un chantier multiforme. État des lieux de la sociologie de la culture dans l'espace germanophone
}

\author{
Winfried Gebhardt \\ Traduction : Pierre Rusch
}

Nous remercions M. Winfried Gebhardt ainsi que la revue Soziologie de nous avoir accordé l'autorisation de traduire ce texte pour le présent numéro.

Wir danken Herrn Winfried Gebhardt und der Zeitschrift Soziologie für die freundliche Genehmigung, diesen Artikel in französischer Übersetzung zu publizieren.

1 La sociologie a entretenu et entretient aujourd'hui encore une relation ambivalente avec ce domaine de la vie humaine qu'on a coutume d'appeler la «culture». Cette dernière s'est révélée une pierre d'achoppement depuis les débuts de la discipline. Si la plupart de ses représentants voyaient effectivement dans la culture - c'est-à-dire le vaste domaine des idées et de leurs formes d'expression et d'action dans la sphère sociale, politique, économique et esthétique - une composante nécessaire de la vie humaine, ils se refusaient à lui accorder une influence significative sur les évolutions sociales. Soit ils se conformaient à la vulgate marxiste traditionnelle, selon laquelle la culture doit être considérée comme un simple phénomène de superstructure enraciné dans des fondations économiques surpuissantes, soit ils reprenaient la position fondamentale d'Émile Durkheim, pour qui le social ne s'explique que par le social.

\section{La tradition classique de la sociologie allemande de la culture}

2 En ce qui concerne la relation entre culture et société, la sociologie classique allemande occupe une place à part dans l'histoire de la sociologie. On pourrait raconter l'histoire de la sociologie allemande classique comme une histoire de la sociologie de la culture. Il 
allait en effet de soi pour les deux fondateurs de la sociologie allemande, Max Weber et Georg Simmel - mais aussi, avec certaines réserves, pour Ferdinand Tönnies - que tout agir social s'inscrit dans des rapports culturels, et que pour comprendre cet agir social, il faut connaître ces rapports culturels dans leur développement historique et dans leur ancrage institutionnel actuel. C'est pourquoi le terme "sociologie de la culture" n'apparaît que rarement chez les trois auteurs cités (et le cas échéant, dans une acception restreinte, puisqu'il ne désigne alors que la sociologie des arts). À leurs yeux, la sociologie se confondait avec la sociologie de la culture, parce qu'ils lui assignaient pour tâche d'explorer les multiples interactions entre les structures sociales et les schémas d'interprétation culturels. La culture et la société étaient unies par une relation ouverte, non-symétrique et dynamique. Ils ne présupposaient pas que la première devait être simplement déduite de la seconde - par exemple des rapports de classe - d'une manière déterministe, mais ne cédaient pas non plus, comme encore beaucoup de leurs contemporains, à la croyance idéaliste selon laquelle la société était exclusivement dirigée par la culture ${ }^{1}$. La réalité sociale, à l'étude de laquelle ils se consacraient avec tant de passion, leur apparaissait comme une unité composée d'éléments structurels et culturels. Toute culture était à leurs yeux déposée dans des structures sociales, toute structure chargée de contenus culturels, et l'interaction entre ces deux ordres de phénomènes prenait des formes toujours nouvelles ${ }^{2}$.

C'est aussi pour cette raison que Weber et Simmel (Tönnies seulement dans certaines limites) refusaient toutes les conceptions «fermées» de la culture, telles qu'elles avaient cours parmi les tenants d'une philosophie idéaliste de la culture qui déterminait cette dernière comme une totalité sociale fermée et recherchait donc en permanence la "forme supérieure ", une "synthèse stylistique », voire l'" esprit d'une époque ». Disons pour simplifier que les pères fondateurs de la sociologie allemande concevaient la culture comme un phénomène pluriel et dynamique, un processus multiforme et fondamentalement "ouvert». La culture était pour eux un ensemble composé de nombreux éléments différents, de plusieurs facteurs et ensembles de facteurs, dotés chacun de sa dynamique propre, qui ne se fondent pas les uns dans les autres, mais souvent se contrarient et se contredisent les uns les autres - ce qui n'empêchait pas les deux sociologues de s'efforcer de mettre en évidence les forces culturelles déterminantes qui avaient, selon eux, contribué à l'émergence du "monde moderne ». Si l'appareil conceptuel presque héroïque à travers lequel ils tentaient d'appréhender cet état de fait ("tragédie de la culture», "dialectique sans réconciliation" chez Simmel, "polythéisme des valeurs", "lutte éternelle", "charisme " chez Weber) peut sembler aujourd'hui obsolète ${ }^{3}$, la situation que ces concepts décrivent, c'est-à-dire le fait que la culture ne résout pas les oppositions, mais porte toujours et nécessairement en elle des contradictions, des absurdités, des tensions, des conflits, est en revanche toujours d'actualité.

\section{La rupture d'une tradition}

4 Ces convictions fondamentales de la sociologie allemande classique ${ }^{4}$ - que je n'ai fait qu'esquisser ici - allaient être ébranlées dans la période suivante. Il convient en l'espèce de distinguer deux évolutions. Si la sociologie allemande de la République de Weimar continua à envisager la culture et la société dans un rapport permanent d'interaction, l'idée que la culture constituait un processus ouvert et dynamique allait 
en revanche se trouver, avec le postulat méthodologique de la «neutralité axiologique de la science ", de plus en plus écartée, voire discréditée - si l'on excepte des positions marginales comme celle du jeune Helmuth Plessner. La nostalgie d'une nouvelle synthèse culturelle - que l'on ne peut comprendre qu'en la replaçant dans la situation particulière des années 1920 -, la volonté de concevoir à nouveau la culture comme un concept axiologique, et non comme un simple concept analytique, amena les esprits à se détourner des positions de Weber et de Simmel, désormais dénigrés comme "sociologues de la résignation ${ }^{5}$ ", et à s'engager dans une nouvelle ontologisation, ou une resubstantialisation du concept de culture. Ce fut le cas de Ferdinand Tönnies et d'Alfred Weber - ce dernier usurpant le concept de "sociologie de la culture » pour baptiser son propre programme sociologique -, mais aussi de Max Scheler, Arnold Gehlen, Hans Freyer et même Karl Mannheim, qui tous se remirent en quête de la vérité. Si Mannheim, avec sa théorie des espaces d'expérience conjonctifs, cherchait des chemins vers le Vrai sans absolutiser un point de vue particulier ${ }^{6}$, les autres auteurs visaient au contraire à fonder scientifiquement un tel point de vue absolu. Ils trouvaient cette valeur de référence dans l'idée, exaltée par les romantiques, d'une communauté fermée, notamment au plan culturel. Afin de légitimer cette idée, dont la réalisation représentait pour la plupart d'entre eux également un objectif politique, ils développèrent des conceptions dualistes plus ou moins rigoureuses, qui leur permettaient de caractériser la société de leur temps en termes de "crise", de "stade de désagrégation" ou de "décadence ", et de faire valoir la nécessité d'un homme nouveau, d'une "nouvelle communauté » dotée d'une «culture nouvelle ${ }^{7}$ ». Parmi les plus connues de ces dichotomies figurent le couple " communauté chaude " / société froide » forgé par Tönnies, encore opératoire aujourd'hui, ainsi que l'opposition, alors extrêmement répandue, entre " civilisation occidentale » et « culture allemande 8 ".

5 Des préoccupations semblables animaient le groupe qui se constitua à cette époque sous la dénomination d'«École de Francfort ». Celle-ci restait également prisonnière d'une perspective dualiste, c'est-à-dire axiologique. Walter Benjamin et Theodor W. Adorno, par exemple, opéraient une distinction nette, sur le plan esthétique, entre les valeurs culturelles élevées, dites "auratiques", et les productions d'une "culture de masse " manipulée par l'industrie culturelle ${ }^{9}$ ". Cette ligne de pensée mène jusqu'à Habermas et à sa vision dualiste d'un "système » opposé au "monde vécu » (où la culture connaît son épanouissement et son émancipation véritables), mais on en trouve également des traces dans des approches plus récentes comme les cultural studies ${ }^{10} \mathrm{ou} \mathrm{le}$ " postmodernisme » de Mike Featherstone ${ }^{11}$, qui sont toujours à la recherche de formes d'expression culturelle «authentiques" (auratiques) et les trouvent souvent dans les subcultures « subversives ${ }^{12} »$.

6 La sociologie américaine, en revanche, et notamment la théorie structuro-fonctionnelle de Talcott Parsons, qui dominait le paysage théorique dans les premiers temps de la République fédérale, raya presque entièrement de son programme l'idée, issue de la sociologie classique, d'une interaction permanente entre la société et la culture. Se référant à l'anthropologie culturelle classique telle qu'elle avait été développée en Amérique notamment par Franz Boas, Margaret Mead ou Ruth Benedict ${ }^{13}$, Parsons partait du principe que "toute société dispose d'un fonds de valeurs et de normes communes, qui englobe et intègre la subdivision des rôles, des groupes et des institutions ${ }^{14}$ ». S'il attribuait donc à la culture une fonction d'intégration décisive, il considérait cependant que cette culture constituait une réalité établie en toute 
certitude, et ne réclamait donc aucun examen approfondi. «Qu'il n'était pas permis de conclure de l'évidence non problématique de la culture dans les sociétés primitives une évidence d'ailleurs toute relative même dans ce contexte - au caractère non problématique de la culture en général, il [Parsons] n'y prit pas garde. La théorie structurelle s'est développée dans la croyance assurée que toute société produit sa propre culture intégratrice ${ }^{15}$.» Et parce que ce processus s'effectue d'une manière quasi-automatique, la culture était dans une large mesure inintéressante pour la théorie structuro-fonctionnelle.

$7 \mathrm{Du}$ fait de ces évolutions, l'orientation spécifiquement culturelle de la sociologie allemande classique et la conception de la culture sur laquelle elle se fondait s'étaient pour une grande part perdues dans la sociologie de la République fédérale, et ce jusque dans les années 1970. Peter L. Berger et Thomas Luckmann, dans leur ouvrage La Construction sociale de la réalité ${ }^{16}$ - qui reprenait les traditions de l'« interactionnisme symbolique » et de la phénoménologie -, ainsi que Friedrich $\mathrm{H}$. Tenbruck, dans sa thèse d'habilitation Geschichte und Gesellschaft ${ }^{17}$ [Histoire et société, 1963], avaient pourtant dès les années 1960 préparé le retour de la sociologie de la culture dans la tradition de Max Weber et Georg Simmel. De même, la théorie de la civilisation de Norbert Elias (qui était resté jusque-là plutôt isolé et ignoré dans la discipline) avait commencé à éveiller l'intérêt ${ }^{18}$. Toutefois, c'est seulement dans les années 1980 que la sociologie de la culture s'est trouvée revitalisée aussi sur le plan institutionnel. Depuis cette époque, la culture a de nouveau le vent en poupe dans la sociologie allemande, d'une manière toujours plus marquée. On pourrait aller jusqu'à parler d'une sorte de tournant culturaliste dans la sociologie allemande depuis le milieu des années $1980^{19}$. Dans de nombreux domaines sociaux, la culture a regagné le pouvoir de fascination qu'elle avait au XIX ${ }^{e}$ siècle - avec tous les dangers qui peuvent résulter d'une nouvelle idéalisation.

\section{La revitalisation de la sociologie de la culture en Allemagne}

8 L'histoire de la nouvelle sociologie allemande de la culture commence avec la publication d'un numéro thématique ainsi intitulé par la Kölner Zeitschrift für Soziologie und Sozialpsychologie, et la fondation, en parallèle, d'un groupe de travail au sein de la Deutsche Gesellschaft für Soziologie [DGS], bientôt transformé en une section officielle de cette institution. Les initiateurs de cette entreprise, qui se donnaient pour tâche de ressusciter la tradition ensevelie de la sociologie classique allemande de la culture étaient Friedrich $\mathrm{H}$. Tenbruck (Tübingen), aujourd'hui décédé, et Wolfgang Lipp (Würzburg). Ensemble, ils rédigèrent les articles programmatiques introduisant la nouvelle orientation. Ils étaient secondés notamment par Mohammed Rassem (Salzbourg), Justin Stagl (Salzbourg), Hans-Peter Thurn (Düsseldorf), Alois Hahn (Trier) et Arnold Zingerle (Bayreuth).

9 Cette «nouvelle école allemande de sociologie de la culture ${ }^{20}$ » partait des présupposés ou prémisses suivants, qui constituent aujourd'hui encore son fondement théorique :

1. À l'anthropologie philosophique, telle qu'elle s'est développée de Johann Gottfried Herder à Ernst Cassirer, Helmuth Plessner et Arnold Gehlen, elle emprunte sa vision de l'homme, conçu comme un être de culture qui n'est ni guidé par ses seules dispositions naturelles, ni, grâce à son intelligence, limité à une simple adaptation optimale aux conditions extérieures. Parce qu'il a les moyens, le désir et le besoin de créer une 
culture, l'homme est appelé à construire sa propre réalité à partir d'idées et de valeurs. C'est seulement à travers les significations qu'il donne à ses actes que se constituent pour lui le monde, le Soi et la société. C'est pourquoi toute pratique humaine est aujourd'hui considérée comme culturelle, y compris l'agir purement matériel et utilitaire, qui se trouve lui aussi pris dans le monde de significations symboliques où l'homme vit. Celui-ci n'est pas considéré seulement comme le créateur d'institutions et de règles sociales qui en retour le modèlent, mais tout autant comme le producteur et le produit de significations spirituelles et morales, à l'aide et en vertu desquelles il a même coutume de briser et de modifier les institutions et les règles sociales.

10 2. La culture se réalise dans la société. Parce que l'homme est un être de culture, les relations sociales doivent toujours se transformer en culture, c'est-à-dire développer des significations qui fondent l'agir individuel et social. La culture représente dès lors les schémas de signification caractéristiques dans lesquels se reconnaît l'ensemble de la société, la somme des "réalités admises », la culture globale perçue dans l'évidence de sa tradition sociale. Cela ne concerne cependant pas seulement les différents contenus idéels, mais aussi les formes sociales de leur perpétuation cultuelle et rituelle, ainsi que leur ancrage institutionnel et tout le domaine de leur matérialisation esthétique (y compris dans la sphère de la vie quotidienne).

11 3. Ce concept de culture étendu à l'ensemble de la société se trouve cependant aussitôt révoqué. Il n'est qu'une fiction - certes nécessaire au plan théorique - qui n'a de réalité, au mieux, que dans les sociétés dites "primitives ». L'erreur de la cultural anthropology classique américaine (et de Talcott Parsons à sa suite) a été de conclure de la culture des sociétés "primitives » à celle des sociétés modernes, et de promouvoir ainsi une substantialisation - c'est-à-dire une essentialisation, une totalisation et une territorialisation - de la culture ${ }^{21}$. En effet, dans chaque société, la culture se répartit entre différents groupes sociaux et prend différentes formes. L'opposition entre "culture représentative» et "culture populaire», entre "culture supérieure » et «culture quotidienne» (aujourd'hui, il est vrai, largement dépassée) est l'une des expression de cet état de fait. Percevoir et décrire cette différenciation de la culture dans une société donnée relève toujours d'une analyse empirique. Face à des processus généraux d'individualisation, de pluralisation et de globalisation qui affectent entre autres le domaine de la culture, il incombe précisément à la sociologie de la culture la tâche difficile d'identifier et de décrire de façon adéquate les schémas de différenciation nouveaux, souvent contradictoires, et les syncrétismes culturels qui dans la plupart des domaines de la réalité sociale se recomposent presque quotidiennement.

12 4. La culture est dynamique. La culture n'est pas un objet, mais un tissu de relations, elle se trouve donc constamment en mouvement, en action. Elle ne se développe pas non plus comme une "entité séparée : elle s'exprime dans les rapports, les différentes formes de relations et processus d'échanges au sein de la sociétéé2 ${ }^{2}$. Peut-être même vaudrait-il mieux, pour rendre compte de cette réalité, assigner pour objet à la sociologie de la culture, non plus la «culture », mais le «changement culturel». La discipline doit en tout cas avoir conscience que son objet change constamment de forme; elle doit, selon la formule de Friedrich H. Tenbruck, se garder «de canoniser aucun problème, aucune perspective, aucun domaine particuliers ", et s'interdire " de développer une théorie et une méthode contraignantes à partir d'un phénomène unique $^{23} »$. 
13 De ces postulats de base découle un programme de recherche spécifique, qui assigne pour tâche à la sociologie de la culture ${ }^{24}$

1. L'identification et la "description dense" (Clifford Geertz) des schémas de signification ou des "réalités admises", constituant, à travers tous les domaines d'existence et toutes les institutions, les présupposés et les intentions qui donnent explicitement ou implicitement une assise et un sens à l'agir individuel et social des individus.

14 2. La recherche des causes, des modalités et de l'origine de ces schémas de signification ou de ces « réalités admises ». Pourquoi, comment et où se sont formées telles idées, telles significations, telles valeurs? Sous quelles formes symboliques et dans quelles pratiques apparaissent-elles? Comment se cristallisent-elles en institutions, en dogmes et/ou en préceptes canoniques?

15 3. L'identification des acteurs, de leurs stratégies et de leurs intérêts. Quelles traditions tacites ou explicites déterminent les schémas de signification courants? Qui sont ceux qui les thématisent, les régissent et les légitiment? Comment procèdent-ils et par quels intérêts sont-ils guidés? Quels nouveaux schémas de signification, quelles "réalités admises » ou «fabriquées » voient le jour? Qui les introduit, pour quels motifs, selon quelles stratégies et avec quelles intentions?

16 4. La recherche des configurations et des actions typiques à travers lesquelles les "réalités admises et fabriquées" prennent forme dans la réalité sociale. Quels comportements standardisés, rôles et normes, et quels groupes sociaux (communautés, associations, mouvances) se forment autour de quels schémas de signification? Comment ces groupes sont-ils organisés et structurés? Quelle est la relation entre le centre et la périphérie, entre l'élite et les simples suiveurs? Quelles formes de communication utilisent-ils typiquement?

17 5. La description et l'analyse des objets d'usage courant (de l'automobile à l'architecture et autres productions artistiques, en passant par les vêtements et l'aménagement de l'habitat) dans lesquels se matérialisent les "réalités admises et fabriquées ». Qu'est-ce qui est "branché », qu'est-ce qui est "ringard », et pourquoi ? Quelles sont les préférences des individus en matière d'esthétique quotidienne (modes) ? Comment se transforment-elles, et qui orchestre leurs transformations?

18 6. L'analyse de la signification culturelle de ces « réalités admises et fabriquées ». Sur quelle logique et quelle dynamique se fondent-elles? Quel pouvoir exercent-elles sur les actes des individus, sur les institutions sociales et sur l'évolution de la société ?

Une sociologie de la culture qui pose de telles questions dépasse, d'une part, les limites étroites des spécialités au sein des sciences sociales; elle ne se conçoit pas comme une " sociologie de » qui ne s'intéresserait qu'aux processus de production esthétique dans les activités théâtrales, musicales, littéraires et artistiques, ou encore à la production des idées religieuses, philosophiques et scientifiques. Elle est, d'autre part, nécessairement vouée à collaborer avec d'autres sciences de la culture, et notamment avec l'histoire, parce qu'il n'est pas possible de développer une problématique en termes de sociologie de la culture sans une connaissance approfondie des contextes historiques $^{25}$. La collaboration n'est pas moins nécessaire avec l'ethnologie et l'ethnographie, la science des religions, la théologie, les études littéraires, musicales et artistiques. La sociologie de la culture se conçoit en ce sens comme une discipline 
autonome de réflexion théorique et de recherche, d'orientation fondamentalement interdisciplinaire, au sein de la sociologie.

\section{Les axes théoriques au sein de la sociologie allemande de la culture}

Si cette "nouvelle école allemande de sociologie de la culture » a contribué de façon décisive à établir la recherche culturelle au sein de la sociologie allemande, elle doit à présent affronter la concurrence d'autres approches qui se définissent elles aussi comme "socioculturelles». La sociologie allemande de la culture est actuellement en plein essor et intègre avidement certaines impulsions venues d'autres traditions théoriques nationales. En cela, elle ne fait toutefois souvent - comme dans le cas de la réception des écrits de Clifford Geertz ${ }^{26}$ - que réimporter sous un léger travestissement les thèmes de la sociologie allemande classique. Il faut mentionner ici d'une part la théorie de Pierre Bourdieu, qui, avec son concept d'habitus ${ }^{27}$, a notamment influencé de manière très forte les travaux sur la structure sociale et sur le genre, et d'autre part, les postmodernistes américains regroupés autour de Mike Featherstone et de la revue Theory, Culture and Society, qui analysent dans une perspective néo-marxiste les potentialités destructrices de la culture capitaliste de masse. Signalons aussi les cultural studies $^{28}$, les club-culture studies ${ }^{29}$ et les public-culture studies ${ }^{30}$ anglo-saxonnes, qui, dans une perspective plus déconstructiviste, s'intéressent principalement aux schémas de signification et aux pratiques symboliques « authentiques » développés par les cultures populaires et les groupes subculturels; il s'agit ici de mettre en lumière la « lutte pour la signification " (Lawrence Grossberg) et pour le "pouvoir de définition esthétique » qui, selon ces chercheurs, ferait rage dans l'époque moderne. À cela s'ajoute l'émergence, parallèlement à l'institutionnalisation de la nouvelle sociologie de la culture largement inspirée de Max Weber, d'un certain nombre d'autres écoles se réclamant de traditions théoriques semblables, sinon identiques: une "sociologie phénoménologique de la culture» qui se nourrit des travaux d'Alfred Schütz et de Thomas Luckmann, une "sociologie philosophique de la culture», inspirée principalement de la pensée de Helmuth Plessner, et une «théorie de la civilisation » dans le prolongement des recherches de Norbert Elias.

D'une manière générale, on peut donc dire que la recherche culturelle a pris pied dans la sociologie de langue allemande. Ce faisant, néanmoins, elle s'est tellement ramifiée, elle a tant perdu ses contours, qu'elle ne peut plus guère être décrite comme un phénomène homogène. La culture est devenue un colifichet dont chacun aime à se parer, même la théorie des systèmes. On ne s'aventurera pas sans un certain goût du risque à proposer la classification suivante. Il est possible de distinguer :

1. Une sociologie de la culture fondée sur la « théorie de l'action » et largement inspirée du programme de recherche wébérien. Je rattache à ce courant, outre les noms cités plus haut, Johannes Weiß (Kassel), Klaus Lichtblau (Kassel), Karl-Siegbert Rehberg (Dresde), Eckhart Pankoke (Essen) et bien d'autres. Ce groupe domine jusqu'aujourd'hui la section «Sociologie de la culture » de la Deutsche Gesellschaft für Soziologie, il dispose de son propre organe de publication (Sociologia Internationalis, ainsi qu'une partie de la revue italo-allemande Annali di Sociologia / Soziologisches Jahrbuch) et d'une collection spécifique dirigée par Justin Stagl («Schriften zur Kultursoziologie», aux Éditions Dietrich Reimer de Berlin). 
2. Une "sociologie phénoménologique de la culture ", étroitement liée aux conceptions théoriques d'Alfred Schütz et de Thomas Luckmann. J'y rattache, outre Luckmann luimême, principalement Hans-Georg Soeffner (Constance), Walter L. Sprondel (Tübingen), Jörg R. Bergmann (Gießen), Jo Reichertz (Essen), Hubert Knoblauch (Constance), Anne Honer (St-Gallen), Ronald Hitzler (Dortmund), Thomas S. Eberle et Christoph Maeder (l'aile suisse du mouvement), et bien d'autres encore. Ce groupe n'a pas de position établie au sein de la Deutsche Gesellschaft für Soziologie, il navigue entre plusieurs sections. Tout au plus pourrait-on désigner la section «Sociologie du langage " (récemment rebaptisée «Sociologie de la connaissance») comme son port d'attache. La collection « Materiale Soziologie », dirigée par Thomas Luckmann, HansGeorg Soeffner et Jörg R. Bergmann (chez Walter de Gruyter) peut être considérée comme sa base éditoriale. La collection «Passagen und Transzendenzen » dirigée par Michael N. Ebertz aux Éditions universitaires de Constance, ainsi que la collection «Erlebniswelten» dirigée par Winfried Gebhardt, Ronald Hitzler et Franz Liebl chez Leske+Budrich, font pour ainsi dire le lien entre ces deux premières écoles, très proches tant au plan théorique qu'au plan thématique.

3. Une «sociologie philosophique de la culture" nourrie de l'«anthropologie philosophique » de Helmuth Plessner, mais aussi de l'esthétique de Walter Benjamin et Theodor W. Adorno qui, outre des thèmes anthropologiques (anthropologie et sociologie des sens, de la violence, etc.), traite avant tout de sujets relatifs à l'histoire des idées et de la culture. J'y range l'actuel représentant de la section « Sociologie de la culture » de la DGS, Wolfgang Eßbach (Fribourg en Br.), Michael Makropoulos (Berlin / Würzburg), Thomas Konrad (Göttingen), Joachim Fischer (Dresde) et beaucoup d'autres.

4. Une sociologie de la culture issue elle aussi du champ phénoménologique, mais plus portée vers le «constructivisme » du fait de l'intégration d'éléments structuralistes (empruntés à Michel Foucault, Pierre Bourdieu et en partie même à Niklas Luhmann). Le haut-lieu de ce courant est l'Université de Bielefeld, et ses principaux représentants sont entre autres Karin Knorr-Cetina, Richard Grathoff, Klaus Amann et Stefan Hirschauer.

5. Une «école bourdieusienne» allemande, qui influence à l'heure actuelle profondément la recherche sur la structure sociale et sur le genre. Quoique cette orientation s'efforce d'intégrer des approches issues de la théorie de l'action et de la sociologie de la connaissance, la référence dominante reste l'idée fondatrice de Bourdieu selon laquelle la culture doit s'interpréter comme l'expression de rapports de pouvoir et d'intérêts. J'inclus dans cette école, outre Gerhard Schulze (Bamberg), Michael Vester (Hanovre) et Thomas Müller-Schneider (Bamberg), avant tout HansPeter Müller (Berlin), Sighard Neckel (Siegen), Herbert Willems (Kassel) et beaucoup d'autres.

6. Une sociologie de la culture tournée vers la «théorie de la civilisation », qui s'appuie sur les travaux de Norbert Elias et s'efforce d'intégrer, outre certains emprunts à la psychanalyse et à l'histoire des mentalités, des fragments théoriques de la sociologie bourdieusienne de la culture. Au sens strict, ce groupe comprend notamment des chercheurs comme Hermann Korte (Hambourg), Gabriele Klein (Hambourg), Peter Gleichmann (Hanovre), auxquels il faudrait cependant ajouter, dans une perspective plus large, Ingo Mörth et surtout Gerhard Fröhlich. En tant que chefs de file de la section « Théorie culturelle et recherche culturelle » de la Österreichische Gesellschaft für Soziologie, ces derniers veillent sur cette orientation depuis Linz - avec le soutien de la 
collection dans laquelle ils publient les résultats des symposiums d'études culturelles de Linz. Leurs intérêts ne se limitent toutefois pas à cette problématique, et portent plus largement sur une synthèse de différentes approches de la sociologie de la culture.

7. Un groupe diffus, parce qu'encore non structuré, de jeunes sociologues rassemblés autour de Rainer Winter (Aix-la-Chapelle) et Udo Göttlich (Duisburg), qui essayent de faire connaître, d'ancrer institutionnellement et de traduire en études empiriques spécifiques (portant notamment sur la culture des médias), le programme des cultural studies développé par Stuart Hall.

\section{Les thèmes de recherche de la sociologie allemande de la culture}

Les thèmes de recherche ne se laissent pas plus facilement ordonner que le paysage théorique. Sans prétendre à l'exhaustivité, et sans exclure des chevauchements partiels, je vois se dessiner à l'heure actuelle les centres d'intérêt suivants :

1. Un retour sur les traditions sociologiques dans le contexte de l'histoire européenne et nord-américaine des idées et de la culture, avec une insistance particulière sur la comparaison entre les courants de pensée allemands et français d'une part, allemands et américains d'autre part.

2. Le prolongement des conceptions théoriques des différentes orientations. Les sujets principaux sont l'étude a) des fondements anthropologiques; b) des processus de médiation culturelle et de leurs agents (fondateurs, mécènes, sympathisants, etc.); c) des mécanismes et des stratégies de préservation de la culture établie (la tradition, la création de canons, la mentalité, l'habitus, les institutions, la mémoire collective, etc.) ; d) de l'apparition et du développement de nouvelles entités, comme par exemple les différentes « scènes culturelles ».

31 3. Le développement de méthodes non standardisées, spécifiquement adaptées aux problématiques de la sociologie de la culture. L'accent principal porte ici sur les procédés herméneutiques et ethnographiques, sur ce que Clifford Geertz a appelé la "description dense", ainsi que sur des approches issues de l'ethnographie et des cultural studies: l'analyse photo et vidéo et la participation observante qui doit désormais se substituer à « l'observation participante ».

4. L'étude de la signification des éléments culturels pour l'analyse des structures sociales, en particulier pour le développement de nouveaux systèmes de classification qui ne se limitent pas aux indicateurs classiques (profession, revenus, niveau d'éducation), mais incluent des facteurs culturels tels que les échelles de valeurs, les critères esthétiques, les styles de vie. Aux analyses classiques par strates sociales se substituent ici de plus en plus les analyses en termes de milieux et de styles de vie.

5. Les études théoriques et empiriques sur les processus actuels de transformation culturelle: l'esthétisation, la muséalisation, la désacralisation, la fabrication d'événements, la monumentalisation (en particulier dans l'architecture des bâtiments publics), l'importance grandissante accordée à l'expérience vécue et au corps, ainsi que les formes d'expression sociale de ce nouvel intérêt.

6. Les études empiriques (historiques et contemporaines) sur les formes sociales de transmission et de confirmation de l'appartenance culturelle - par exemple les rituels, 
les cérémonies, les fêtes et les célébrations, les coutumes, la conception de l'honneur et des vertus sociales.

7. Les études empiriques (historiques et contemporaines) sur la place des cultures minoritaires dans le champ de tensions entre « culture représentative (supérieure) » et "culture populaire ou quotidienne». Ce domaine comprend les études communautaires, qui ont connu un renouveau ces dernières années, mais aussi les analyses de certains groupes unis par un style de vie, les analyses de différentes "scènes culturelles » aussi bien dans la culture supérieure (par exemple l'étude du public des festivals de musique classique et d'opéra) que dans la culture populaire, sportive et juvénile (le milieu des amateurs de parcs d'aventures ou de bistrots, des passionnés de techno, de hip-hop, de motos, de sports de glisse et d'escalade, etc.).

8. Les analyses consacrées à la culture religieuse du présent (notons au passage que la sociologie de la culture inclut nécessairement des questions relevant de la sociologie des religions, mais peut très bien laisser de côté la sociologie des Églises). On s'intéresse tout particulièrement aux processus dits de spiritualisation (depuis le renouveau de la mystique chrétienne jusqu'au retour des pratiques et des doctrines ésotériques), aux syncrétismes religieux, ainsi qu'à la culture religieuse quotidienne en ce qu'elle ne se laisse pas réduire à la dogmatique ecclésiale officielle.

9. L'identification et l'analyse du substrat social d'un «sens culturel nouveau ». Ce substrat comprend d'un côté des mouvements sociaux et/ou charismatiques, des subcultures, des cultures juvéniles, des clubcultures, et d'un autre côté, des groupes attachés à ressusciter des valeurs culturelles disparues (groupes fondamentalistes et régionalistes).

10. L'étude des cultures de la technologie, des médias et de la communication. Les travaux dans ce domaine mènent, au-delà des questions spécifiques à la sociologie de la culture, sur le terrain de la sociologie de la technique, du langage et des médias. Leur large spectre s'étend de réflexions d'ordre plutôt théorique sur la «mémoire communicationnelle » à des études sur la fonction et les effets culturels des médias de masse modernes jusqu'à des enquêtes sur la culture des " communautés virtuelles » et sur les retombées socio-culturelles des progrès de la technologie génétique.

39 11. Des études de sociologie de l'art et de la musique (comme celles menées par l'Institut Mediacult, en lien étroit avec le Wiener Institut für Musiksoziologie), qui prennent pour thème les changements intervenus dans la production et la réception de l'art et de la musique, dans un contexte de globalisation de l'industrie culturelle.

12. Des études de politique culturelle, qui cherchent à appréhender et à décrire, outre les évolutions connues (décloisonnement national, démocratisation, assujettissement grandissant à l'économie du fait du sponsoring culturel, etc.), les stratégies d'intervention et de légitimation des acteurs du management culturel comme des responsables politiques dans ce domaine.

\section{Remarque finale}

41 Si divers que soit aujourd'hui le paysage de la sociologie de la culture dans l'espace germanophone, il trouve son unité - malgré toutes les divergences de détail (qui sont entre autres politiques) - dans une vision de la culture comme un " processus ouvert " porté par un développement incessant. La culture, pourrait dire le sociologue pour 
pousser le raisonnement jusqu'au bout, n'est rien d'autre que la définition que les humains en donnent. Sous quelque variante qu'elle se présente, la sociologie de la culture s'est depuis longtemps détournée de tout concept essentialiste ou substantialiste de la culture, même si le reproche d'essentialisme est parfois prononcé dans l'affrontement entre les diverses écoles. Des acteurs marginaux comme les représentants des cultural studies, en particulier, croient encore devoir se démarquer en portant une telle accusation. Quoi qu'il en soit, la culture est aujourd'hui presque unanimement considérée en sociologie comme un "processus libre et ouvert ", dont les contours concrets doivent être en permanence redéfinis sur le plan empirique. Aussi la recherche en sociologie de la culture ne verra-t-elle pas de sitôt s'épuiser ses objets ou ses thématiques. C'est une des raisons qui font de la sociologie de la culture l'un des axes de recherche les plus stimulants et les plus novateurs au sein de la sociologie institutionnelle.

\section{BIBLIOGRAPHIE}

Appadurai, A. / Breckenridge, C. (1988) : «Why Public Culture? », Public Culture I/1, p. 5-9.

Berger, P. / Luckmann, T. (1986) : La Construction sociale de la réalité, trad. P. Taminiaux, Paris : Klincksieck (rééd. A. Colin, 1996).

Bormann, R. (1998) : “ "Spaß ohne Grenzen”. Kulturtheoretische Reflexionen über einen europäischen Themenpark », Sociologia internationalis, 36 (1), p. 33-60.

Bourdieu, P. (1989) : La Distinction. Critique du jugement social, Paris : Éditions de Minuit. Bourdieu, P. (2010) : Zur Soziologie der symbolischen Formen, Francfort-sur-le-Main : Suhrkamp. Breuer, S. (1995) : Ästhetischer Fundamentalismus. Stefan George und der deutsche Antimodernismus, Darmstadt.

Elias, N. (2003) : La Civilisation des mœurs et La Dynamique de l'Occident, Paris : Pocket (Agora).

Featherstone, M. (1992) : «Postmodernism and the Aestheticization of Everyday Life », dans : Lash, S. / Friedman, J. (éd.) : Modernity and Identity, Oxford/Cambridge, p. 265-287.

Gebhardt, W. (1994) : « Soziologie aus Resignation. Über den Zusammenhang von Gesellschaftskritik und Religionsanalyse in der deutschen Soziologie der Jahrhundertwende ", Leviathan. Zeitschrift für Sozialwissenschaft, 22, p. 520-540.

Gebhardt, W. (1996) : « Der Splitter im Auge des Nachbarn. Historische, systematische und methodologische Überlegungen zum Verhältnis von Soziologie und Geschichtswissenschaft », dans : Fössel, A. / Kampmann, C. :Wozu Historie heute ?Beiträge zu einer Standortbestimmung im fachübergreifenden Gespräch, Cologne / Weimar / Vienne, p. 97-122.

Gebhardt, W. (1999) : « "Warme Gemeinschaft” und "Kalte Gesellschaft”. Zur Kontinuität einer deutschen Denkfigur », dans : Meuter, G. / Otten, R. (éd.) : Der Aufstand gegen den Bürger. Antibürgerliches Denken im 20. Jahrhundert, Würzburg, p. 165-184. 
Geertz, C. (1983) : «La description dense. Vers une théorie interprétative de la culture », dans : id. : Bali. Interprétation d'une culture, trad. D. Paulme et L. Evrard, Paris : Gallimard.

Geertz, C. (1992) : « Kulturbegriff und Menschenbild», dans : Habermas, R. / Minkmar, N. (éd.) : Das Schwein des Häuptlings, Berlin, p. 52-82.

Greverus, I. M. (1978) : Kultur und Alltagswelt. Eine Einführung in die Fragen der Kulturanthropologie, Munich.

Grossberg, L. (1995) : «Cultural Studies : What is a Name (One more Time)», Taboo, n¹, p. 1-37. Jameson, F. (2007) : Le Postmodernisme, ou la logique du capitalisme tardif, trad. Fl. Nevoltry, Paris, ENSBA.

Kamphausen, G. (1993) : « Charisma und Heroismus. Die Generation von 1890 und der Begriff des Politischen ", dans : Gebhardt, W. / Ebertz, M. N. / Zingerle, A. (éd.) : Charisma. Theorie, Religion, Politik, Berlin / New York, p. 221-246.

Karp, I. / Muller-Craemer, C. / Lavine, S. D. (éd.) (1992) : Museums and Community. The Politics of Public Culture, Washington/Londres.

Kroeber, A. L. / Kluckhohn, C. (1967) : Culture. A Critical Review of Concepts and Definitions, New York.

Lepsius, R. M. (1986) : «Interessen und Ideen. Die Zurechnungsproblematik bei Max Weber », Kölner Zeitschrift für Soziologie und Sozialpsychologie, hors-série $n^{\circ} 27$, Opladen, p. 20-31 ; trad. fr. dans ce numéro de ce numéro de Trivium (12|2012).

Lethen, H. (1994) : Verhaltenslehren der Kälte. Lebensversuche zwischen den Kriegen, Francfort-sur-leMain.

Lichtblau, K. (1996) : Kulturkrise und Soziologie. Zur Genealogie der Kultursoziologie in Deutschland, Francfort-sur-le-Main.

Lichtblau, K. (2001) : « Soziologie als Kulturwissenschaft? Zur Rolle des Kulturbegriffs in der Selbstreflexion der deutschsprachigen Soziologie », Soziologie. Forum der Deutschen Gesellschaft für Soziologie, 1, p. 5-21.

Lipp, W. / Tenbruck, F. H. (1979) : « Zum Neubeginn der Kultursoziologie », Kölner Zeitschrift für Soziologie und Sozialpsychologie, 3, p. 393-398.

Lipp, W. (1994) : Drama Kultur, Berlin.

Mannheim, K. (1980) : « Eine soziologische Theorie der Kultur und ihrer Erkennbarkeit (Konjunktives und kommunikatives Denken)», dans : Kettler, D. / Meja, V. / Stehr, N. (éd.) : Strukturen des Denkens, Francfort-sur-le Main, p. 155-322.

Morley, D. / Chen, K.- H. (éd.) (1996) : Stuart Hall. Critical Dialogues in Cultural Studies, Londres / New York.

Müller, H.-P. (1986) : « Geschmack und Distinktion. Grundzüge der Kultursoziologie Pierre Bourdieus ", Kölner Zeitschrift für Soziologie und Sozialpsychologie, hors-série n²7, Opladen, p. 162-190.

Reckwitz, A. (2000) : Die Transformationen der Kulturtheorien. Zur Entwicklung eines Theorieprogramms, Weilerswist.

Redhead, S. (éd.) (1998a) : The Clubcultures Reader : Readings in Popular Cultural Studies, Oxford.

Redhead,S. (1998b) : Subculture to Clubcultures : An Introduction to Popular Cultural Studies, Oxford. 
Rehberg, K.-S. (1986) : « Kultur versus Gesellschaft ? Anmerkungen zu einer Streitfrage in der deutschen Soziologie ", Kölner Zeitschrift für Soziologie und Sozialpsychologie, hors-série $n^{\circ} 27$, Opladen, p. 92-115.

Scheler, M. (1963) : «Ernst Troeltsch als Soziologe », dans : id. : Gesammelte Werke, t. VI : Schriften zur Soziologie und Weltanschauungslehre, $2^{\mathrm{e}}$ éd. Berne / Munich, p. 377-390.

Simmel, G. (1999) : Philosophie de l'argent, trad. S. Cornille et Ph. Ivernel, Paris : PUF (coll. Quadrige).

Stagl, J. (1986) : « Über den Einfluß kultureller Inhalte auf die sozialen Strukturen », Zeitschrift für Politik, 2, p. 115-147.

Steil, A. (1993) : Krisensemantik. Wissenssoziologische Untersuchungen zu einem Topos moderner Zeiterfahrung, Opladen.

Tenbruck, F. H. (1979) : « Die Aufgaben der Kultursoziologie », Kölner Zeitschrift für Soziologie und Sozialpsychologie, 3, p. 399-421 ; trad. fr. dans ce numéro de Trivium (12|2012).

Tenbruck, F. H. (1986) : Geschichte und Gesellschaft, Berlin.

Tenbruck, F. H. (1996) : Perspektiven der Kultursoziologie. Gesammelte Aufsätze, éd. par C. Albrecht et al., Opladen.

Thornton, S. (1995) : Club Cultures : Music, Media and Subcultural Capital, Cambridge.

Weber, M. (1965) : Essais sur la théorie de la science, trad. J. Freund, Paris : Plon.

Wiggershaus, R. (1993) : L'École de Francfort. Histoire, développement, signification, trad. L. Deroche, Paris : PUF.

\section{NOTES}

1. Cf. en particulier les écrits de Max Weber sur la théorie de la science (Weber [1965]), dans lesquels le sociologue part en guerre contre les positions citées ; voir aussi la préface de Simmel à sa Philosophie de l'argent, où l'auteur se donne pour tâche le dépassement du matérialisme historique (cf. Simmel [1999]).

2. Cf. à ce sujet Lepsius (1986).

3. Cette terminologie héroïque montre de surcroît combien il était difficile pour Weber et Simmel de se détacher de la conception idéaliste que le XIX ${ }^{\mathrm{e}}$ siècle se faisait de la culture. $\mathrm{Cf}$. à ce sujet Kamphausen (1993); Gebhardt (1994).

4. Voir l'exposé détaillé de Lichtblau (1996), ainsi que Lichtblau (2001).

5. Scheler (1963), p. 377.

6. Cf. Mannheim (1980).

7. Cf. Lipp (1994), p. 251 sqq. ; Gebhardt (1999).

8. Cf. à ce sujet Breuer (1995), p. 184 sqq. ; Lethen (1994) ; Steil (1993).

9. Cf. Wiggershaus (1993).

10. Cf. Grossberg (1995).

11. Cf. Featherstone (1992); Jameson (2007).

12. Cf. Lipp (1994), p. 253.

13. Cf. Greverus (1978); Kroeber / Kluckhohn (1967).

14. Tenbruck (1979), p. 408 (trad. mod.).

15. Ibid.

16. Berger / Luckmann (1986). 
17. Tenbruck (1986), (1996).

18. Elias (2003).

19. Cf. désormais Reckwitz (2000)

20. Cf. Tenbruck (1979), p. 401 sqq. ; Rehberg (1986) ; Stagl (1986).

21. Cf. Bormann (1998), p. 47 sq.

22. Lipp (1994),p. 76.

23. Tenbruck (1979), p. 405 (trad. mod.).

24. Sur le développement suivant, cf. Lipp / Tenbruck (1979), p. 395 sqq.

25. Cf. à ce sujet Gebhardt (1996).

26. Cela vaut naturellement en premier lieu pour Geertz (1983) ; cf. aussi Geertz (1992).

27. Bourdieu (1989); Müller (1986).

28. Cf. Morley / Chen (1996).

29. Cf. Redhead (1998b), (1998a) ; Thornton (1995).

30. Cf. Appadurai / Breckenridge (1992).

INDEX

Mots-clés : sociologie de la culture,

Schlüsselwörter : Kultursoziologie,

\section{AUTEURS}

\section{WINFRIED GEBHARDT}

Winfried Gebhardt (né en 1954) est professeur de sociologie à l'université de Coblence-Landau. Pour plus d'informations, voir la notice suivante. 